\title{
Perdas germinativas na colheita mecanizada do milho cultivado em espaçamentos reduzido e convencional
}

\section{Losses in germination mechanized harvest of corn grown in small spacing and conventional}

\author{
Danilo Roberto Loureiro ${ }^{1}$; Haroldo Carlos Fernandes²; Mauri Martins Teixeira ${ }^{3}$; \\ Daniel Mariano Leite ${ }^{4 *}$; Lara Santana Fernandes ${ }^{5}$
}

\section{Resumo}

Objetivou-se com este trabalho, avaliar as perdas no potencial germinativo de sementes em função da colheita mecanizada do milho cultivado com espaçamentos entre linhas de semeadura convencional $(0,90 \mathrm{~m})$ e reduzido $(0,45 \mathrm{~m})$, submetida a diferentes velocidades de deslocamento da colhedora e aberturas do sistema debulhador. O cultivar de milho utilizado foi o DKB 747. O delineamento experimental foi o de blocos casualizados em esquema fatorial $2 \times 3 \times 3$ com três repetições. Os tratamentos foram constituídos por dois espaçamentos entre linhas da cultura $(0,45$ e $0,90 \mathrm{~m})$, três velocidades de deslocamento da colhedora $\left(1,8 ; 3,5 \mathrm{e} 4,1 \mathrm{~km} \mathrm{~h}^{-1}\right)$ e três aberturas entre o côncavo e o cilindro debulhador $(25,30$ e $35 \mathrm{~mm})$. A germinação média das sementes debulhadas manualmente, cultivadas com espaçamento entre linhas de semeadura de 0,45 e $0,90 \mathrm{~m}$, foi de 78,45 e 74,12\%, respectivamente. A germinação das sementes de milho não é influenciada pelos diferentes espaçamentos entre linhas de semeaduras. A menor abertura entre o cilindro debulhador e o côncavo resulta nos menores valores de germinação. A velocidade de deslocamento da colhedora de $1,8 \mathrm{~km} \mathrm{~h}^{-1}$ utilizada no espaçamento entre linhas de semeadura de 0,9 m resulta em menores valores de germinação das sementes de milho. Palavras-chave: Germinação, máquinas agrícolas, colheita, Zea mays $L$

\begin{abstract}
The objective of this study was to evaluate the germination potential losses due to the mechanized harvest of corn grown with row spacing of conventional seeding $(0.90 \mathrm{~m})$ and low $(0.45 \mathrm{~m})$ under different travel speeds of harvester thresher and openings in the system. The cultivar used was the DKB 747. The experimental design was randomized blocks in scheme $2 \times 3 \times 3$ with three replications. The treatments were two row spacing of culture $(0.45$ and $0.90 \mathrm{~m})$, three harvester travel speeds $(1.8$, 3.5 and $4.1 \mathrm{~km} \mathrm{~h}-1)$ and three openings between the concave and threshing drum $(25,30$ and $35 \mathrm{~mm})$. The average germination of threshed manually planted with planting spacing of 0.45 and $0.90 \mathrm{~m}$, was 78.45 and $74.12 \%$ respectively. The germination of corn seeds is not influenced by different row spacing plantings. The smallest gap between the cylinder and concave thresher results in lower levels of germination. The speed of the harvester $1.8 \mathrm{~km} \mathrm{~h}-1$ used in planting spacing of $0.9 \mathrm{~m}$ resulting in lower germination of corn.
\end{abstract}

Key words: Germination, agricultural machinery, harvest, Zea mays $L$

\footnotetext{
${ }^{1}$ Eng $^{\circ}$ Agrícola e Ambiental, Doutorando em Engenharia Agrícola, Dept ${ }^{\circ}$. de Engenharia Agrícola, Universidade Federal de Viçosa, UFV, Viçosa, MG. E-mail: loudanilo@yahoo.com

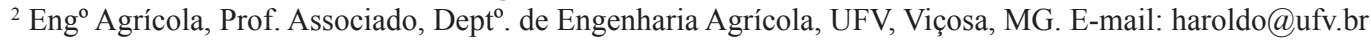

${ }^{3}$ Eng $^{\circ}$ Agr $^{\circ}$, Prof. Associado, Dept ${ }^{\circ}$. de Engenharia Agrícola, UFV, Viçosa, MG. E-mail: mauri@ufv.br

${ }^{4}$ Lic. em Ciências Agrícolas, Doutorando em Engenharia Agrícola, Dept ${ }^{\circ}$. de Engenharia Agrícola, UFV, Viçosa, MG. E-mail: dm.leite@hotmail.com

${ }^{5}$ Eng $^{\mathrm{a}}$ de Alimentos, Mestranda em Engenharia Agrícola, Dept ${ }^{\mathrm{o}}$. de Engenharia Agrícola, UFV, Viçosa, MG. E-mail: lara. fernandes@ufv.br

* Autor para correspondência
} 


\section{Introdução}

A produção brasileira de milho no ano de 2010 foi de 54,14 milhões de toneladas, o que confere o terceiro lugar na produção mundial. Desse total produzido, cerca de 4,6 milhões de toneladas são exportadas (ANEC, 2010). A produtividade brasileira de 4,13 $\mathrm{t} \mathrm{ha}^{-1}$ é considerada baixa, quando comparada a países como Estados Unidos e China que possuem produtividade média de 10,59 e 5,29 $\mathrm{t} \mathrm{ha}^{-1}$, respectivamente (USDA, 2010).

A densidade de plantas ideal para maximizar o rendimento de grãos de milho varia de 30.000 a 90.000 plantas ha $^{-1}$. Essa densidade depende da disponibilidade hídrica, da fertilidade do solo, do ciclo do cultivar, da época de semeadura e do espaçamento entre linhas (SANGOI et al., 2006; GUARESCHI et al., 2008; KVITSCHAL et al., 2010).

Segundo Argenta, Silva e Sangoi (2001) o arranjo espacial das plantas de milho constitui-se em uma prática importante no manejo, pois permite a obtenção de produtividades próximas ao potencial genético da cultura. Dourado Neto et al. (2003) observaram que o menor espaçamento entre linhas de milho propiciou aumento na produtividade de grãos. Esse aumento foi atribuído à minimização da competição entre as plantas pela radiação solar.

$\mathrm{Na}$ operação de debulha do milho manual ou mecânica ocorrem danos nas sementes e por isso essa operação é considerada uma das maiores responsáveis pela redução na qualidade das sementes. Segundo Araújo (1995), os danos mecânicos, decorrentes de impactos e abrasões, podem apresentar-se claramente visíveis na forma de rupturas e fragmentações das sementes, as quais são eliminadas durante o beneficiamento, reduzindo a produção.

As perdas qualitativas e os danos mecânicos compreendem as sementes quebradas, trincadas, rachadas e a redução na sua germinação e vigor. Os danos mecânicos se manifestam não só pela aparência física das sementes afetadas, como também pelas consequências provocadas pelos danos internos sobre a sua qualidade fisiológica (PINHEIRO NETO; GAMERO, 2000).

Vários fatores, físicos e biológicos, podem contribuir para que o processo de deterioração do milho instale-se e se acentue sempre que o pericarpo é rompido. As trincas no pericarpo funcionam como portas de entrada para microrganismos, especialmente fungos (MANTOVANI, 1989).

De acordo com Ruffato, Couto e Queiroz (2001) quanto mais seca a semente estiver, menor será a elasticidade do pericarpo, tornando-a mais vulnerável aos danos provenientes da ação dos equipamentos. O sistema de trilha é o grande causador de danos mecânicos nas sementes. Quando a colheita é realizada com umidade abaixo a recomendada, os grãos desprendem-se com mais facilidade do sabugo, porém ficam mais suscetível aos danos mecânicos.

O número de impactos e o local do impacto é outro fator que influencia o grau de injúria mecânica em sementes, contudo não se pode exercer nenhum controle sobre eles, uma vez que é totalmente imprevisível a área da semente na qual ocorreram (CARVALHO; NAKAGAWA, 1988; MENEZES; LERSCH-JUNIOR; STORCK, 2002).

Dessa forma objetivou-se com este trabalho determinar as perdas germinativas nas sementes durante a colheita mecanizada do milho cultivado em espaçamentos reduzido e convencional submetidas a diferentes velocidades de deslocamento da colhedora e aberturas entre o cilindro debulhador e o côncavo.

\section{Material e Métodos}

O experimento foi conduzido no campo experimental da Universidade Federal de Viçosa (UFV), no Município de Coimbra - MG, nas coordenadas 20'51'24" Sul, 4248'10" Oeste, apresentando $720 \mathrm{~m}$ de altitude. O cultivar de milho utilizado neste trabalho foi o DKP 747, que é 
caracterizado por apresentar um ciclo precoce com rápido desenvolvimento radicular e sementes mais duras.

A semeadora, marca "VENCE TUDO", com quatro linhas de semeadura espaçadas a $0,45 \mathrm{~m}$, foi regulada para dosar seis sementes por metro linear. Nos tratamentos em que o espaçamento foi de 0,90 $\mathrm{m}$, retiraram-se duas linhas. Nos tratamentos com espaçamento de $0,45 \mathrm{~m}$, realizou-se a eliminação do excesso de plantas na linha na segunda semana depois da semeadura. O objetivo foi garantir a população de 60.000 plantas por hectare em todas as parcelas.

Para a colheita foi utilizada uma colhedora “LAVRALE", modelo 300, ano 1987, com plataforma de duas linhas de colheita. Durante a colheita, a rotação do cilindro debulhador da colhedora foi mantida constante em $750 \mathrm{rpm}$.

O delineamento experimental foi o de blocos casualizados em esquema fatorial $2 \times 3 \times 3$ com três repetições. Os tratamentos foram constituídos por dois espaçamentos entre linhas da cultura $(0,45$ e $0,90 \mathrm{~m})$, três velocidades de deslocamento da colhedora $\left(1,8 ; 3,5\right.$ e $\left.4,1 \mathrm{~km} \mathrm{~h}^{-1}\right)$ e três aberturas entre o côncavo e o cilindro debulhador $(25,30$ e $35 \mathrm{~mm})$.

Para o espaçamento entre linhas de $0,45 \mathrm{~m}$, a colhedora trabalhou com uma alimentação de duas linhas entre os divisores de linha da plataforma. Nos tratamentos com espaçamento de $0,90 \mathrm{~m}$, a colhedora trabalhou normalmente, ou seja, com alimentação de uma linha entre os divisores de linha da plataforma.

Antes de iniciar a colheita, o diâmetro médio das espigas foi determinado com o auxílio de um paquímetro. Essa medida foi realizada em cinco sabugos escolhidos aleatoriamente em cada unidade experimental. O conhecimento desse parâmetro possibilita a regulagem adequada da abertura entre o cilindro debulhador e o côncavo, responsáveis pelo sistema de trilha na colhedora.
Para determinação da altura da inserção da primeira espiga foram avaliadas cinco amostras aleatórias em cada unidade experimental. Com uma trena, foi determinada a altura média da inserção da primeira espiga em relação ao solo. Tal procedimento objetiva controlar a altura da plataforma de colheita, visando reduzir as perdas quantitativas.

As sementes foram colhidas com um teor de água médio de 20\%, em base úmida. Esse teor de água foi determinado em laboratório, por meio de um medidor de umidade da marca "Gehaka", modelo G800.

Para a análise qualitativa foram coletadas amostras de sementes (1 kg aproximadamente) no graneleiro da colhedora. A avaliação das perdas qualitativas foi realizada pelo teste de germinação. Como os valores de germinação foram baixos, não se justificou a realização de testes para análise do vigor.

Para realização do teste de germinação, foram utilizadas 150 sementes, com três repetições de 50 sementes por tratamento. O substrato utilizado foi o rolo de papel, com três folhas de papel Germitest, com a quantidade de água equivalente a 2,5 vezes a sua massa. $\mathrm{O}$ germinador foi regulado para manter a temperatura constante a $30{ }^{\circ} \mathrm{C}$, conforme as Regras para Analises de Sementes (BRASIL, 2009).

A primeira contagem das sementes germinadas foi realizada 85 horas após a incubação. Como não foi possível detectar diferenças das plântulas normais das anormais, foi necessário realizar uma segunda contagem realizada 180 horas após a incubação, e os resultados foram expressos em porcentagem de germinação.

Após a realização da análise de variância, as médias foram comparadas de acordo com o teste de Tukey em nível de 5\% de significância. 


\section{Resultados e Discussões}

Com a caracterização da planta de milho, é possível regular a abertura entre o cilindro debulhador e o côncavo, a altura da plataforma de colheita e a rotação de trabalho. Para tanto, foi avaliado o diâmetro das espigas, a altura de inserção da primeira espiga e a umidade das sementes um dia antes de realizar a colheita. A média e o coeficiente de variação dos parâmetros citados foram calculados para cada bloco e são apresentados na Tabela 1.

Tabela 1. Diâmetro médio das espigas ( $\mathrm{mm})$, altura de inserção da primeira espiga (cm) e teor de água dos grãos (\%), para espaçamento convencional e reduzido.

\begin{tabular}{llllllll}
\hline \multirow{2}{*}{ Bloco } & \multirow{2}{*}{ Espaçamento } & \multicolumn{2}{c}{$\varnothing$ médio } & \multicolumn{3}{c}{ Alt. da inserção } & \multicolumn{2}{c}{ Teor de água } \\
\cline { 3 - 7 } & & Média & CV & Média & CV & Média & CV \\
\hline 1 & $0,45 \mathrm{~m}$ & 49,11 & 4,90 & 85,67 & 10,55 & 21,52 & 8,63 \\
1 & $0,90 \mathrm{~m}$ & 50,51 & 8,14 & 74,82 & 12,19 & 21,32 & 5,30 \\
2 & $0,45 \mathrm{~m}$ & 49,76 & 5,64 & 83,47 & 16,38 & 20,29 & 5,78 \\
2 & $0,90 \mathrm{~m}$ & 50,18 & 6,94 & 90,76 & 9,65 & 19,56 & 7,57 \\
3 & $0,45 \mathrm{~m}$ & 50,58 & 3,84 & 78,22 & 8,60 & 20,27 & 6,31 \\
3 & $0,90 \mathrm{~m}$ & 53,64 & 5,22 & 88,24 & 9,55 & 19,64 & 6,87 \\
\hline
\end{tabular}

CV - coeficiente de variação

Fonte: Elaboração dos autores.

Para que se possa realizar a debulha, a espiga deve entrar na abertura entre o cilindro e o côncavo e ser friccionada de maneira a separar os grãos do sabugo. Para isso, a abertura entre o cilindro debulhador e o côncavo se reduz entre a entrada da espiga e a saída. Na Tabela 1 pode-se observar, por meio do coeficiente de variação, que houve uniformidade no diâmetro das espigas no campo.

Com base na altura da inserção da primeira espiga, coletada no momento da colheita, podese regular a altura da plataforma de colheita. Os valores mínimos da altura de inserção da primeira espiga foram tomados como referência. Adotou-se uma altura da plataforma de colheita de $0,5 \mathrm{~m} \mathrm{em}$ relação ao solo. Pretendeu-se com isso, fazer com que menor quantidade de material, que não seja grão, entre nos mecanismos internos da colhedora.

O teor de água das sementes é um fator de fundamental, importância para se obter a regulagem adequada da colhedora. Dependendo da umidade, a força necessária para separá-las do sabugo torna-se diferente. Algumas medidas, como alterar a rotação do cilindro debulhador podem ser adotadas. A rotação do cilindro debulhador foi regulada para 750 rpm. Essa rotação é recomendada pelo fabricante da máquina para as condições na umidade de colheita apresentada na Tabela 1.

Antes de iniciar a colheita, foi retirada uma amostra representativa de cada unidade experimental. As sementes de milho debulhadas manualmente foram utilizadas para comparar as perdas de germinação com as sementes de milho debulhadas pela colhedora.

A germinação média das sementes debulhadas manualmente, cultivadas com espaçamento entre linhas de semeadura de 0,45 e $0,90 \mathrm{~m}$, foi de 78,45 e 74,12\%, respectivamente. Na Tabela 2 é apresenta a análise de variância da germinação das sementes colhidas pela colhedora. 
Tabela 2. Análise de Variância para a germinação de sementes milho colhidas mecanicamente.

\begin{tabular}{ccccc}
\hline Fontes de Variação & GL & Soma de Quadrados & Quadrado Médio & F \\
\hline Blocos & 2 & 515,42 & 257,71 & $2,92^{\text {ns }}$ \\
E & 1 & 65,19 & 65,19 & $0,74^{\text {ns }}$ \\
V & 2 & 202,78 & 101,39 & $1,15^{\text {ns }}$ \\
A & 2 & 729,99 & 364,99 & $4,14^{*}$ \\
E x V & 2 & 585,30 & 292,65 & $3,32^{*}$ \\
E x A & 2 & 471,42 & 235,71 & $2,67^{\text {ns }}$ \\
V x A & 4 & 830,89 & 207,72 & $2,35^{\text {ns }}$ \\
E x V x A & 4 & 667,93 & 166,98 & $1,89^{\text {ns }}$ \\
Resíduo & 34 & 2995,09 & 88,09 & \\
\hline Total & 53 & & & \\
\hline
\end{tabular}

*Significativo ao nível de 5\% de probabilidade; ns - não significativo; E - Espaçamento entre linhas de plantio; V - Velocidade de deslocamento da colhedora; A - Abertura entre o cilindro debulhador e o côncavo.

Fonte: Elaboração dos autores.

A abertura entre o cilindro debulhador e o côncavo bem como a interação entre o espaçamento entre linhas de semeadura e a velocidade de deslocamento da colhedora apresentaram diferenças significativas na análise da germinação. Na Tabela 3 são apresentados os resultados do teste de Tukey para as aberturas entre o côncavo e o cilindro debulhador com redução de germinação das sementes.

A abertura de $30 \mathrm{~mm}$ proporcionou os maiores valores de germinação, ficando com uma média de 45,11\%. Mesmo assim, a germinação apresentouse muito baixa quando comparada com a das sementes colhidas manualmente que apresentaram valores médios de 78,45 e 74,12\% nos tratamentos com espaçamentos entre linhas de 0,45 e $0,90 \mathrm{~m}$ respectivamente.
A abertura de $25 \mathrm{~mm}$ apresentou os menores valores de germinação. $\mathrm{O}$ fato da menor abertura entre o côncavo e o cilindro debulhador causar um aumento na força de atrito sofrida pela espiga pode ter aumentado os danos mecânicos causados nas sementes durante o processo de debulha, reduzindo sua viabilidade, resultado divergente ao de Araújo (1995) que observou que a germinação das sementes colhidas e debulhadas manualmente não se diferenciou das sementes colhidas manualmente e debulhadas mecanicamente.

$\mathrm{Na}$ Tabela 4, é apresentado o teste de média da interação da velocidade de deslocamento da colhedora e o espaçamento entre linhas de semeadura para a germinação de sementes.

Tabela 3. Valores médios de germinação das sementes de milho em função da abertura entre o côncavo e o cilindro debulhador.

\begin{tabular}{cl}
\hline Abertura entre o côncavo e o cilindro debulhador $(\mathrm{mm})$ & Médias (\%) \\
\hline $\mathrm{A}_{1}=25$ & $37,18 \mathrm{~B}$ \\
$\mathrm{~A}_{2}=30$ & $45,11 \mathrm{~A}$ \\
$\mathrm{~A}_{3}=35$ & $37,44 \mathrm{AB}$ \\
\hline
\end{tabular}

$\mathrm{Q}(0,05 ; 34)=3,466$; Diferença Mínima Significativa $=7,6686$; Médias seguidas pela mesma letra não diferem estatisticamente entre si, pelo teste de Tukey a $5 \%$.

Fonte: Elaboração dos autores. 
Tabela 4. Germinação das sementes de milho em função da interação da velocidade de deslocamento com o espaçamento entre linhas de semeadura.

\begin{tabular}{ccc}
\hline $\mathrm{V} \backslash \mathrm{E}$ & $0,45 \mathrm{~m}$ & $0,90 \mathrm{~m}$ \\
\hline $1,8 \mathrm{~km} \mathrm{~h}^{-1}$ & $42,22 \mathrm{~A} \mathrm{a}$ & $32,37 \mathrm{~B} \mathrm{~b}$ \\
$3,5 \mathrm{~km} \mathrm{~h}^{-1}$ & $37,41 \mathrm{~A} \mathrm{a}$ & $43,63 \mathrm{~A} \mathrm{a}$ \\
$4,1 \mathrm{~km} \mathrm{~h}^{-1}$ & $43,41 \mathrm{~A} \mathrm{a}$ & $40,44 \mathrm{~A} \mathrm{a}$ \\
\hline
\end{tabular}

As letras maiúsculas se referem à comparação entre as medias das linhas, enquanto que as letras minúsculas se referem às colunas Fonte: Elaboração dos autores.

Observa-se que a velocidade de deslocamento da colhedora de $1,8 \mathrm{~km} \mathrm{~h}^{-1}$ utilizada no espaçamento convencional apresentou os menores valores de germinação. Os mecanismos internos da colhedora trabalham independentes da velocidade de deslocamento, porém, a menor velocidade de deslocamento fez com que a taxa de alimentação dos mecanismos fosse a menor. Esse fato pode ocasionar um maior tempo de permanência das sementes dentro da colhedora, aumentando os danos causados nas sementes. Verifica-se também, que as velocidades de 3,5 e 4,1 $\mathrm{km} \mathrm{h}^{-1}$ não apresentaram diferenças significativas quando utilizadas em diferentes espaçamentos entre linhas de semeadura.

A germinação quando se utilizou o espaçamento de semeadura de $0,45 \mathrm{~m}$ não apresentou diferenças significativas para as diferentes velocidades de deslocamento da colhedora.

A diferença entre os resultados da colheita manual com a colheita mecanizada mostra que os danos mecânicos causados nas sementes pela colhedora durante a colheita foram intensos, inviabilizando, neste caso, a produção de sementes, pois somente as colhidas manualmente obtiveram valores toleráveis de germinação acima de $70 \%$. Porém, em ambas as situações os valores médios de germinação ficaram abaixo dos padrões comerciais estipulados pelo Ministério da Agricultura Pecuária e Abastecimento que é de $85 \%$ (BRASIL, 2012).

\section{Conclusões}

A germinação das sementes de milho não é influenciada pelos diferentes espaçamentos entre linhas de semeaduras.

A menor abertura entre o cilindro debulhador e o côncavo resulta em menor germinação.

A velocidade de deslocamento da colhedora de $1,8 \mathrm{~km} \mathrm{~h}^{-1}$ utilizada no espaçamento entre linhas de semeadura de $0,9 \mathrm{~m}$ resulta em menores valores de germinação das sementes de milho.

\section{Referências}

ARAÚJO, R. F. Efeito da colheita mecanizada nas perdas quantitativas e qualitativas de sementes de milho (Zea mays, L.). 1995. Tese (Doutorado em Agronomia/ Fitotecnia) - Universidade Federal de Viçosa, Viçosa, 1995.

ARGENTA, G.; SILVA, P. R. F.; SANGOI, L. Arranjo de plantas em milho: análise do estado-da-arte. Ciência Rural, Santa Maria, v. 31, n. 6, p. 1075-1084, 2001.

ASSOCIAÇÃO NACIONAL DOS EXPORTADORES DE CEREAIS - ANEC. Área, estatisticas. 2010. Disponível em: <http://www.anec.com.br/links.html>. Acesso em: 15 set. 2011.

BRASIL. Ministério da Agricultura e da Reforma Agrária. Regras para analise de sementes. Brasília: SNDA/DNDV/CLAV, 2009. 398 p.

- Ministério da Agricultura Pecuária e Abastecimento. Padrões para produção e comercialização de sementes de milho. 2012. Disponível em: <http:// extranet.agricultura.gov.br/sislegis-consulta/servlet/ VisualizarAnexo?id=10811>. Acesso em: 7 maio 2012. 
CARVALHO, N. M.; NAKAGAWA, J. Sementes: ciência, tecnologia e produção. 3. ed. Campinas: Fundação Cargill, 1988. 424 p.

DOURADO NETO, D.; PALHARES, M.; VIEIRA, P. A.; MANFRON, P. A.; MEDEIROS, S. L. P.; ROMANO, M. R. Efeito da população de plantas e do espaçamento sobre a produtividade de milho. Revista Brasileira de Milho e Sorgo, Sete Lagoas, v. 2, n. 3, p. 63-77, 2003.

GUARESCHI, R. F.; GAZOLLA, P. R.; PERIN, A.; ROCHA, A. C. Produção de biomassa de milho silagem em função do arranjo populacional e adubação. Revista Ciência Agronômica, Fortaleza, v. 39, n. 3, p. 468-475, 2008.

KVITSCHAL, M. V.; MANTINE, E.; VIDIGAL FILHO, P. S.; VIDIGAL, M. C. G.; SCAPIM, C. A. Arranjo de plantas e produção de dois híbridos simples de milho. Revista Ciência Agronômica, Fortaleza, v. 41, n. 1, p. 122-131, 2010.

MANTOVANI, E. C. Colheita mecânica do milho. In: FUNDAÇÃO CARGILL. Colheita mecânica, secagem e armazenamento do milho. Campinas, Fundação Cargill, 1989. p. 1-24. (Serie técnica, 2).
MENEZES, N. L.; LERSCH-JUNIOR, I.; STORCK, L. Qualidade física e fisiológica das sementes de milho após beneficiamento. Revista Brasileira de Sementes, Londrina, v. 24, n. 1, p. 97-102, 2002.

PINHEIRO NETO, R.; GAMERO, C. A. Efeito da colheita mecanizada nas perdas qualitativas de sementes de soja. Engenharia Agrícola, Jaboticabal, v. 20, n. 3, p. 250-257, set. 2000 .

RUFFATO, S.; COUTO, S. M.; QUEIROZ, D. M. Análise de impactos em grãos de milho pelo método de elementos finitos. Revista Brasileira de Armazenamento, Viçosa, v. 26, n. 1, p. 21-27, 2001.

SANGOI, L.; ERNANI, P. R.; SILVA, P. R. F.; HORN, D.; SCHMITT, A.; SCHWEITZER, C.; MOTTER, F. Rendimento de grãos e margem bruta de cultivares de milho com variabilidade genética contrastante em diferentes sistemas de manejo. Ciência Rural, Santa Maria, v. 36, n. 3, p. 747-755, 2006.

UNITED STATES DEPARTMENT OF AGRICULTURE - USDA. Area, yield, and production. 2010. Disponível em: <http://www.usda.gov>. Acesso em: 15 set. 2011. 
